Article

\title{
Cross-Cultural Pragmatic Competence in an EFL Context for a Sustainable Learning Environment: A Case of Northern Cyprus
}

\author{
Ben Bardis ${ }^{1, *}$, Fatoş Silman ${ }^{1}$ and Behbood Mohammadzadeh ${ }^{2}$ \\ 1 Educational Sciences, Faculty of Education, Cyprus International University, Mersin 10, \\ Nicosia 99258, Turkey; fsilman@ciu.edu.tr \\ 2 ELT Department, Faculty of Education, Cyprus International University, Mersin 10, Nicosia 99258, Turkey; \\ behbudm@ciu.edu.tr \\ * Correspondence: benbardis29@gmail.com
}

check for

updates

Citation: Bardis, B.; Silman, F.; Mohammadzadeh, B. Cross-Cultural Pragmatic Competence in an EFL Context for a Sustainable Learning Environment: A Case of Northern Cyprus. Sustainability 2021, 13, 10346. https://doi.org/10.3390/su131810346

Academic Editors: Ana B. Bernardo, Adrian Castro-Lopez, Javier Puente, Leandro Almeida and Marc A. Rosen

Received: 16 July 2021

Accepted: 11 September 2021

Published: 16 September 2021

Publisher's Note: MDPI stays neutral with regard to jurisdictional claims in published maps and institutional affiliations.

Copyright: (c) 2021 by the authors. Licensee MDPI, Basel, Switzerland. This article is an open access article distributed under the terms and conditions of the Creative Commons Attribution (CC BY) license (https:// creativecommons.org/licenses/by/ $4.0 /)$.

\begin{abstract}
A review of literature on pragmatic competence reveals that less attention is given to the enrichment of cross-cultural pragmatic awareness in the classroom. The study focuses on the need to survey and discuss communicative dynamics in classroom situations and the importance of enhancing cross-cultural pragmatic competence in the English as a foreign language (EFL) context. We believe that enhancing students' cross-cultural pragmatic competence will provide students with a sustainable learning environment, which is crucial for the quality of education. The investigation involves a mixed approach of quantitative and qualitative methods by using a questionnaire for EFL students and interview guide questions for both EFL students and teachers. For quantitative analysis, the participants involved in this research include 200 EFL students of different nationalities, and for the qualitative analysis, the participants include 10 teachers and 20 EFL students in a university in North Cyprus. The study's findings indicate that students lack cross-cultural pragmatic knowledge and must be provided with classroom activities for social interaction and to develop explicit and implicit communicative competencies in EFL as a target language. Findings further reveal that EFL students are not endowed with cross-cultural pragmatic competence by the EFL teachers who provide little attention to pragmatic knowledge and classroom activities in the EFL context.
\end{abstract}

Keywords: cross-cultural pragmatic competence; social context; communicative dynamics in classroom situations; EFL context

\section{Introduction \\ Background Study}

There is a close relationship between language and culture, which requires the knowledge of cultural norms in an act of effective communication. Thus, language is the basis of culture since one depends on the other. In this sense, language must be taught alongside cultural norms and values in order to help speakers of diverse languages communicate across cultures. In addition to the knowledge of the language, EFL students should be provided with the features of pragmalinguistics and socio pragmatics in order to enable them to communicate effectively in English, as they need to communicate in a social context. This requires EFL teachers to take a step further in creating cross-cultural pragmatic awareness with the aim to help their learners enhance their cross-cultural pragmatic competence. This awareness is significant for an effective and sustainable communication environment, which will help avoid pragmatic failure in cross-cultural communication [1].

For an act of effective communication, EFL learners of different cultural backgrounds should be endowed with the knowledge of cross-cultural pragmatics by introducing it in classroom situations. Mey [2] describes pragmatics as the use of language in human communication, which means it is essential for interlocutors to be familiar with the conditions and conventions created by the members of a social community. In other words, pragmatics reflects the conventions and social norms manifested in a language as the 
constituents of sociopragmatics. In a similar manner, LoCastro [3] states that cross-cultural pragmatic competence is the ability to use language effectively in a social context. As for the necessity of the cross-cultural features, Koester and Lustig highlight that "cross-cultural study is one in which researchers compare a particular concept in two or more cultures whose members are having intra-cultural experiences". An "intercultural" study involves interaction among people from two or more cultures" [4]. In divergent global societies, interlocutors of diverse languages may not share the same cultural norms. This results in miscommunication due to the norms of different cultural backgrounds in the social milieu. For this reason, it is essential for EFL teachers to help their students enhance cross-cultural pragmatic competence. In contrast to the traditional pragmatic competence, Taguchi states that "the surge of transnationalism and multiculturalism, has inevitably challenged the traditional notion of pragmatic competence" [5]. For Mulyana [6] and Dash [7], cross-culture is described as an intercultural relation by representatives of different cultural backgrounds for communication harmony through L2 in social circumstances. As a result, it renders it difficult for those with cross-cultural pragmatic competence to exchange information and communicate appropriately in another language.

With respect to this, few studies have been published in this field of pragmatics involving students in Northern Cyprus. One of these few studies conducted in Northern Cyprus focuses on the pragmatic competence of Kurdish EFL undergraduate students in Northern Iraq in the use of request and apology strategies [8]. In another research study by Mohammadzadeh et al. [9], they looked into how Turkish ELT students in the Faculty of Education at Cyprus International University comprehend "Conversational Implicatures". Considering these studies, the researcher discovered a gap in the study of pragmatics in a university with multilingual students from more than 100 different countries. In this study, the focus is on both students' and teachers' cross-cultural pragmatic competence, necessary for successful communication in a social context. This is another aspect of the present study, which makes it original and contributes to the related field.

Timpe [10] and Levine [11] point out how language usage is dynamic in classroom situations, especially in interlingual and multilingual settings, and point out that pragmatic competence involves cultural norms and values. Rafieyan [12] presumes that the cultural characteristics of a target language as in the EFL context could be an important factor for establishing the level of pragmatic dynamics of L2 learners in the target language. In another study, this is exemplified by Röver [13] as "it is hot over here" and may intricate conflicting interpretations of the literal meaning of the expression in different contexts as it may imply "a complaint of a situation, or a weather condition" or a "request for a fan" or "a suggestion to move to a different environment. In this concept, the pragmatic competence involves the comprehension of "what is said, what is heard and what is meant" for successful communication [3]. In this context, the research of Dash [7] suggests reinforcing oral and written communicative activities that are in line with pragmatic knowledge in order to arouse cross-cultural awareness in classroom circumstances.

This study highlights EFL learners' perception and communication dynamics associated with cross-cultural pragmatic competence. It also involves the interaction of EFL teachers and learners in classroom situations where students face critical challenges of cross-cultural differences such as cultural shocks, misunderstandings, disagreements, intimidation and misinterpretation. This study aims to show the significant role of crosscultural communicative competence among EFL learners in using words and expressions in line with cultural norms and values. The study also aims at ascertaining EFL learners' competence regarding cultural norms for effective interaction in English. The study seeks to find answers to the following research questions:

1. What is the competency level of EFL learners on comprehension of pragmatic competence regarding their gender, language group (mother tongues), fields of studies and age?

2. What are the perceptions of EFL learners on cross-cultural pragmatic competence?

3. What are the key challenges to EFL learners in cross-cultural communication? 
4. What are the personal views and experiences of both EFL teachers and their students on cross-cultural pragmatic in classroom situations?

\section{Theoretical Framework}

\section{Perception on Cross-Cultural Pragmatic Competence in EFL Classroom Context}

The literature review in this study entails some essential definitions of cross-cultural pragmatic competence, the important perceptions of EFL teachers and learners concerning cross-cultural pragmatic competence and the key challenges of cross-cultural pragmatic competence in the EFL context. Students' awareness of cross-cultural pragmatics is essential in the EFL context. Integrating cross-cultural communication in EFL classes helps students develop the ability to communicate in a social context [7]. It helps avoid some challenges such as misconception, misinterpretation and misunderstanding during the interaction of two or more different cultures. Thus, teaching and learning a target language must not be separable from its cultural norms and values. Hence, it is not sufficient for the EFL teachers to teach only the grammar part of the target language, but they must also help students enhance cross-cultural pragmatic competence awareness. Jie [14] claims that language teachers must focus on three points when teaching culture in EFL classes: (a) helping students become familiar with cross-cultural differences; (b) helping students tolerate each other's culture by considering the cultural norms and values in the target language; and (c) helping students to learn the target language along with its culture. Teachers' task of making students understand the different cultural norms and values in the EFL context is essential for learners to understand what seems polite in one culture and impolite in a different culture. Thus, using a word or an expression may be morally acceptable in one culture and not in another. In this perspective, Bouchard [15] affirms that the challenges of cross-communication often occur when the felicity conditions are not respected.

The sociolinguist, James [16], describes cross-cultural pragmatic competence as using words and expressions concerning societal norms and conventions of the target language. Thus, cross-cultural pragmatic competence is the ability to use language by acquiring the meaning of words and expressions through context and sociocultural embedding. Chen et al. [17] conducted a discourse completion test (DCT) for Taiwanese and American students at the university level; the finding indicates different cultural resentments from the different nationals that seem to be concerns raised in social circumstances due to cultural differences and misinterpretations. With respect to this, Taj-eddin Mogadam [18] and Benadla [19] discovered the need to bestow communicative competency on EFL learners in classroom circumstances and highlight a teaching approach called "competency-base" in order to rekindle L2 learners for effective communication in a social context. Moreover, cross-cultural communication actively takes solid ground in the tourist industry, where Borni [20] proclaims in his research that the English language by cultural norms and values tends to promote tourism by drawing both the US and the UK close to Algeria and most African countries. By using an example, Guo [21] indicates some similarities in crosscultural behavior between American students and Chinese students with respect to direct and indirect refusal to request and order by "nodding or shaking one's head" as a response and may signify a direct or indirect acceptance or concern in language interpretation. On gender, Maccoby [22] explains that "gender differences generally show the higher performance of women on verbal tasks and men on spatial tasks". Thus, this assumption implies that female interlocutors are more indulged in thorough communication and, as such, are favourably correlated with more affirmative responses to the target language (TL) or L2, as well as EFL. In the domain of gender issues in communication, the author Maccoby [22] lays emphasis that female communicators develop more interest in language learning. With respect to this concept, oral communicative skills must be built up among males and females by using numerous functional platforms of pragmatic routines in order to innovate conversational situations involving the native and the non-native speakers taking part in role-play activities that can establish cross-cultural understanding among the EFL learners. The author confirms that, in gender differences, male communicators, as 
well as language learners, could demonstrate less optimistic manners than female language learners who show a higher level of interaction with others.

Equally, in the EFL classroom context, the research of Gulzar [23] draws our attention to the interaction between Pakistani students and teachers in terms of code-switching from mother tongue (L1) to EFL (English as a Foreign Language) and vice versa by cultural socialization. Corresponding to the classroom situation, Bensen and Cavusoglu [24] also drew our attention to the effectiveness of EFL classroom code-switching in Northern Cyprus that could impart on students' level of communication with regard to the pragmatic context. Admittedly, the research of Ishihara and Cohen [25] sensitizes on the academic preparedness of EFL teachers and how practical it seems to deliver cross-cultural pragmatic knowledge to the EFL learners for communicative competency.

Morgan [26] and Ishihara and Cohen [25] bring to light the exposures of classroom interactive activities involving communicative tasks such as role-plays, pair-work, reading original English materials, presentation in English language and imitating native English speakers' pronunciation in order to develop cross-cultural communication and to enhance pragmatic competence of EFL learners. In another development, Wu [27], Weeger [28] and Sunal [29] raised concerns on strategies involving the basic principle of Communicative Language Teaching (CLT), which is a student-centered approach for enhancing explicit and implicit communicative competencies of EFL. By using an example, in an interactive conversation involving immigrants, "is Pope a Catholic?" by [13], a declaration is aroused that is not part of the conversation but is suddenly used as a definite answer to a question, and the meaning implies "Yes, of course" or "It is so" or "Yes indeed" or "No doubt about that". These associative meanings introduce intricate pragmatic challenges, leaving cross-cultural communicators in suspense.

Therefore, with all the concerns raised in the literature review, the purpose of the paper is (a) to examine the dynamics of cross-cultural pragmatic competence among EFL learners, (b) to examine the perception of EFL learners in cross-cultural pragmatic competence, (C) to examine the key challenges in cross-cultural communication among EFL learners and (d) to examine the personal views and experience of both teachers and students of cross-cultural pragmatics in the classroom situation.

\section{Method}

This part of the research study presents the mixed methods of quantitative and qualitative analyses deployed in the study. Denzin [30] affirms that mixed-methods research (MMR) must practically project pragmatism as a prototype for social research and must be eventually detached from the philosophical foundations of pragmatism. Henceforth, the method includes the instruments and population, data collection instruments, data collection procedure and data analysis method.

\subsection{Instruments}

The instruments for the investigation comprise a questionnaire and interview questions. The questionnaire and the interview questions have been tested on pilot basis. The questionnaire has been administered on pilot basis to twenty five (30) undergraduate students in their first year comprising 13 females and 12 males from various faculties of physical sciences and social sciences who voluntarily responded to the questionnaire. Moreover, 5 teachers and 10 students responded to the interview questions and $40 \mathrm{~min}$ to $45 \mathrm{~min}$ were spent on each respondent. The pilot test provided us feedback for restructuring the questionnaire and the interview questions in terms of content, instructions and sentence structure after contacting three experts in the field of this research for advice and to determine the reliability and validity of the findings in this study. The questionnaire for the investigation involves three parts. Part one comprises the demographic information. Part two comprises the questionnaire, and it contains three sections (A, B and C). Section (A) is composed of ten questions (1-10) of the multiple-choice discourse completion test (MDCT) for meaningful interpretation. It is relevant to research question 1: "What is the competency 
level of EFL learners on comprehension of Pragmatic competence in regard to their gender, language group (mother tongues), fields of studies and age?" The cross-cultural pragmatic competency level test of 10 questions is marked over 100; each question is for 10 marks. An example from the questionnaire is the following.

Simon asks about his fiancée Paulina from his friend David:

Simon: "You know. I've been trying to know if you went out with Paulina."

David: "Paulina is not really my type."

*What does David probably mean?

A. He is not sure of his emotions

B. He is talking bad about Paulina as he does not like her

C. Paulina is somehow his best type

D. They did not go out.

Section B comprised five items: questions (1-5). It is relevant to research question 2: "What are the perceptions of EFL learners on cross-cultural pragmatic competence?" Moreover, Section C comprised five items, questions (6-10), and they are relevant to research question 3 of the paper: "What are the key challenges to EFL learners in crosscultural communication?" Moreover, the answers relative to questions (1-5) in section (B) and questions (6-10) in section (C) are chosen from the options (A, B, C and D) that seem suitable to each item, for example, $1=\mathrm{SA}$ : Strongly Agree; 2 = A: Agree; $3=\mathrm{N}$ : Neutral; 4 = D: Disagree; 5 = SD: Strongly Disagree. Hence, part one and part two of the questionnaire are relevant to the study's quantitative analysis. An example from the questionnaire includes the following: "Cross-cultural communicators experience emotional interference due to clashes of norms and values of different cultures.

In addition, part three includes interview questions relevant to the qualitative analysis related to research question 4: "What are the personal views and experiences of both EFL teachers and their students on cross-cultural pragmatic in classroom situations?" There are four questions composed for EFL teachers, and another four questions composed for EFL learners. The interview was conducted separately for the teachers and learners respondents and the students' respondents. For reference, both the questionnaire and the interview question guides are found on the Appendix A of this study. An example for teachers include the following: "What are the challenges or benefits your students face in cross-cultural communication in classroom situations?" Example for Students: "What are the challenges or difficulties, or benefits your students face in cross-cultural communication with student colleagues in the classroom?

\subsection{Participants}

The participants are 200 respondents comprising 88 male students and 112 female students categorized under positive sciences ( 94 students) and social sciences (106 students) from different continents: Africa, Asia, Europe, America and others. For the participants of the interview section, category (A) comprises 10 teachers, and category (B) presents 20 students. The abbreviations or the acronyms (FT) represent female teachers and (MT) for a male teacher. There are 6 female teachers and 4 male teachers. Category B also involves 20 international students with different cultural backgrounds such as African Francophone, African Anglophone, African Arabic, Asian Arabic and European Turkish cultures. Therefore, the abbreviation (SP) represents student participants, and the participants are numbered from 1 to 20 .

\subsection{Data Collection Procedures}

The process of answering the questionnaire by students was administered under the permission and control of the EFL lecturers on 7 May 2019. Subsequently, permission was granted, and convenient dates were arranged to precisely conduct both the teachers' and students' interviews on the 9 and 10 May 2019. The interviews were conducted in the English language for 10 EFL teachers and 20 EFL students. Moreover, 45 to $50 \mathrm{~min}$ was spent on each participant. The dates for taking the data seem appropriate since 
it was a revision week and most of the students were present and preparing for their end of semester exams in June 2019 and also presumably might have experienced some cross-cultural interactions with one another from the beginning of the semester.

The data of this research were collected in 2019. With the COVID-19 pandemic process that started in 2020, our university, similarly to other universities, has switched mainly to online education. However, due to economic reasons, most of the international students stayed in North Cyprus and did not return to their homeland. Therefore, face-to-face education continued with these students. The researchers believe that this study still has validity in 2021 since interactive classroom activities for developing cross-cultural communication and enhancing the pragmatic competence of EFL learners continued to have significance. Moreover, our university hosts students from more than 100 different countries; therefore, our multicultural campus is an ideal milieu for students to experience cross-cultural communication and to learn from each other.

\subsection{Data Analysis}

The study uses mixed-method and comprises both quantitative and qualitative analyses. Consequently, the data analysis presents, in the first place, quantitative analysis involving the first three research questions. However, the device of ANOVA (Analysis of Variances) by Fraenkel et al. [31] is used to analyse the differences among the group by means of involving the following: students' competency level with regard to "Gender" on Table 1; students' competency level with regard to "Language group (mother tongues)" on Table 2; students' competency level with regard to "Field of studies" on Table 3 and students' competency level with regard to "Age?" on Table 4. Fraenkel et al. [31] confirmed that ANOVA (Analysis of Variance) is a testing tool that describes and explains the dynamics involving various categories of scenarios that occur in their simplest structures of groups: Gender group, Language group (mother tongue) and Age group. We used ANOVA to observe the differences between groups. The Statistical Package for Social Sciences (SPSS) tool is used to analyse the items on Table 5 comprising (item 1, item 2, item 3, item 4 and item 5) and also the items on Table 6 comprising (item 6, item 7, item 8, item 9 and item 10).

The second part involves qualitative analysis, and according to Seidman [32] and Folkestad [33] qualitative data analysis does not strictly follow clear-cut principles. Still, it depends on the nature of the data and the procedure it takes. As a result, the theory of Creswell [34] for the qualitative analysis includes data organization, data editing, data coding and commonality or prototypes of the participants. The interview questions prepared by the author were administered to the teachers and students, but probing questions were used in the follow up where it was needed. The participants were met individually, and the time used for the interview was approximately 45 to $50 \mathrm{~min}$ on each participant for intact findings. The findings were recorded, coded and written down separately. They are transcribed for analysis and presented in the structured format that presents the qualitative result in themes (for example, Theme 1: "Communicative Tasks in EFL Class by Teachers"). According to Braun and Clark [35], the result of qualitative analysis involves themes to explain participants' views, experiences and perceptions. Thus, we evaluated our qualitative data by applying these criteria. There are two categories of respondents: category (A) for teachers and category and (B) for students and all relevant to the fourth research question of the study. Thus, category (A) comprises ten (10) teachers, and category (B) represents twenty (20) students. The abbreviations or the acronyms (FT) represent the female teacher and (MT) for the male teacher. Furthermore, there are six (6) female teachers representing the following acronyms: FT1, FT2, FT3, FT4, FT5 and FT6. Four (4) male teachers also represented the acronyms of the following: MT1, MT2, MT3 and MT4. 


\section{Findings}

Research Question 1: What is the competency level of EFL learners on comprehension of pragmatic competence concerning their gender, language group (mother tongues), fields of studies and age?

Table 1 involves students' performance on comprehension of pragmatic competence concerning gender. The pragmatic test results in Table 1 show no statistically significant differences between male students and female students regarding pragmatic competence. Nevertheless, comparing the mean indicates that EFL female students have a slightly higher mean in the comprehension of pragmatic competence $(\mathrm{M}=4.9823 ; \mathrm{SD}=2.13384)$ than EFL male students of the lower level $(\mathrm{M}=4.7586 ; \mathrm{SD}=2.33759)$. The finding indicates at the gender level, the EFL female students perform better in cross-cultural pragmatic comprehension than their male counterparts. For Maccoby [22], gender differences generally show the higher performance of women on verbal tasks and men on the spatial task. Thus, this assumption implies that female EFL interlocutors are more indulged in thorough communication and, as such, are favourably correlated with more affirmative responses relative to the target language in a social context.

Table 1. Represents the statistical data concerning students' competency level concerning gender.

\begin{tabular}{cccccc}
\hline Gender & $\mathbf{N}$ & Mean & Std. Deviation & Std. Error Mean & Sig \\
\hline Male & 87 & 4.7586 & 2.33759 & 0.25062 & 0.482 \\
Female & 113 & 4.9823 & 2.13384 & 0.20073 & \\
\hline
\end{tabular}

Table 2 involves the significance of students' performance comprehension of pragmatic competence test regarding language group (mother tongues). The pragmatic test results in Table 2 show no statistically significant differences among EFL students' language group (mother tongues) on comprehension of pragmatic competence. Nevertheless, a comparison of the means of the three language groups English as a second language (ESL), French and Arabic reveals that students from English speaking countries speaking English as a second language (ESL) have a slightly higher mean in performance of pragmatic competence $(\mathrm{M}=5.3200 ; \mathrm{SD}=2.15179)$ than the means of students from Arabic-speaking countries who have medium mean $(\mathrm{M}=4.8932 ; \mathrm{SD}=2.25316)$ and French-speaking countries of the lower mean $(\mathrm{M}=4.4043 ; \mathrm{SD}=2.17355)$. The finding indicates that the EFL students of Anglophone background perform better in cross-cultural pragmatic comprehension than their counterparts of Arabic and Francophone backgrounds, who have shortcomings in cross-cultural pragmatic knowledge.

Table 2. Represents the statistical data concerning students' competency level in regard to language group (mother tongues).

\begin{tabular}{cccccc}
\hline Language Group & $\mathbf{N}$ & Mean & Std. Deviation & Std. Error & Sig \\
\hline English & 50 & 5.32 & 2.15179 & 0.30431 & \\
French & 47 & 4.4043 & 2.17355 & 0.31705 & 0.482 \\
Arab & 103 & 4.8932 & 2.25316 & 0.22201 & \\
Total & 200 & 4.885 & 2.22181 & 0.15711 & \\
\hline
\end{tabular}

The pragmatic test results in Table 3 show no statistically significant differences between EFL regarding the field of studies (positive science students and social sciences students) on comprehension of pragmatic competence. However, comparing the mean shows that EFL Social Sciences students in pragmatic competence have a slightly higher mean of performance of $(\mathrm{M}=4.9714 ; \mathrm{SD}=2.24233)$ than that of $\mathrm{EFL}$ positive sciences students of the lower mean $(\mathrm{M}=4.8191 ; \mathrm{SD}=2.19952)$. The finding indicates that crosscultural pragmatic knowledge is significant in social sciences in classroom circumstances where language abilities are acquired practically to communicate in a social context. 
Table 3. Represents the statistical data concerning students' competency level with regard to field of studies.

\begin{tabular}{cccccc}
\hline Figure 94. & $\mathbf{N}$ & Mean & Std. Deviation & Std. Error Mean & Sig \\
\hline Positive Science & 94 & 4.8191 & 2.19952 & 0.22686 & 0.63 \\
Social science & 105 & 4.9714 & 2.24233 & 0.21883 & \\
\hline
\end{tabular}

Table 4 involves the significance of students' performance on comprehension of pragmatic competence concerning age. The pragmatic test results in Table 4 show that there are statistically significant differences between the age groups of EFL students on the comprehension of pragmatic competence. Therefore, the comparison of the mean indicates that the competency level of EFL students, especially of the age group between 25 and 34, has higher performance on comprehension of pragmatic competence $(M=5$, $3788 ; \mathrm{SD}=2.31228)$ than the age group between 17 and $24(\mathrm{M}=4.6641 ; \mathrm{SD}=2.16123)$. The finding indicates that the performance involving students of maturity age (25-34) is slightly higher than the other age groups $(17-24 ; 35-44 ; 45$ and above). Vividly, by the results of this finding, it is important to note that maturity in terms of age is significant in the competency development of language learners.

Table 4. Represents statistical data concerning students' competency level with regard to age?

\begin{tabular}{cccccc}
\hline Age Group & $\mathbf{N}$ & Mean & Std. Deviation & Std. Error Mean & Sig \\
\hline $17-24$ & 131 & 4.6641 & 2.16123 & 0.18883 & \\
\cline { 3 - 5 } $25-34$ & 66 & 5.3788 & 2.31228 & 0.28462 & \\
\hline
\end{tabular}

Research Question 2: What are the perceptions of EFL learners in cross-cultural pragmatic competence?

Table 5 comprises items (item 1 , item 2, item 3, item 4 and item 5) that are all relevant to research question 2. Hence, in part two of the questionnaire, the five items represent the five questions ( 1 to 5 ) in section (B) of the questionnaire found in Appendix A.

Table 5. Represents item 1, item 2, item 3, item 4 and item 5 relating to questions (1 to 5 ) on the questionnaire and relevant to research question 2.

\begin{tabular}{ccccccccccccc}
\hline & \multicolumn{2}{c}{ SA } & \multicolumn{2}{c}{$\mathbf{A}$} & \multicolumn{2}{c}{$\mathbf{N}$} & $\mathbf{D}$ & \multicolumn{2}{c}{ SD } \\
\hline & $\mathbf{N}$ & $\mathbf{\%}$ & $\mathbf{N}$ & $\mathbf{\%}$ & $\mathbf{N}$ & $\mathbf{\%}$ & $\mathbf{N}$ & $\mathbf{\%}$ & $\mathbf{N}$ & $\mathbf{\%}$ & Mean & S.Dev. \\
\hline Item 1 & 63 & 31.3 & 83 & 41.3 & 15 & 7.5 & 30 & 14.9 & 9 & 4.5 & 3.81 & 1.168 \\
\hline Item 2 & 33 & 16.4 & 88 & 43.8 & 27 & 13.4 & 46 & 22.9 & 6 & 3 & 3.48 & 1.107 \\
\hline Item 3 & 41 & 20.4 & 100 & 49.8 & 24 & 11.9 & 29 & 14.4 & 6 & 3 & 3.71 & 1.046 \\
\hline Item 4 & 42 & 20.9 & 92 & 45.8 & 28 & 13.9 & 34 & 16.9 & 4 & 2 & 3.67 & 1.052 \\
\hline Item 5 & 43 & 21.4 & 85 & 42.3 & 28 & 13.9 & 36 & 17.9 & 8 & 4 & 3.6 & 1.13 \\
\hline Note SA: Strongly Agree; A: Agree; N: Neutral; D: Disagree; SD: Strongly Disagree.
\end{tabular}

Note SA: Strongly Agree; A: Agree; N: Neutral; D: Disagree; SD: Strongly Disagree.

The result of item 1 shows, on Table 5 , that out of 200 respondents, 63 respondents $(31.3 \%)$ strongly agreed; 83 respondents $(41.3 \%)$ agreed; 30 respondents $(14.9 \%)$ disagreed; 6 respondents (4.5\%) strongly disagreed; and 15 respondents $(7,5 \%)$ were neutral in responding to item 1 . The participants' mean is $M=3,81$, and the standard deviation is S.Dev $=1.168$. The finding reveals an average number of EFL students agreeing to the importance of cross-cultural pragmatics in the EFL context because it serves as a motivational factor that can virtually enhance the competency of EFL learners.

Item 2 illustrates, on Table 5, that out of 200 respondents, 33 respondents $(16.4 \%)$ strongly agreed; 88 respondents (43.8\%) agreed; 46 respondents (22.9\%) disagreed; 9 respondents (3.0\%) strongly disagreed; and 27 respondents $(13.4 \%)$ were neutral in respond- 
ing to item 2. The mean of the participants is $M=3.48$, and the standard deviation is S.Dev $=1.107$. The finding shows a positive impression of the EFL students agreeing that cross-cultural pragmatic competence is essential in EFL because it provides an opportunity to EFL learners to communicate and share their personal ideas, thoughts and feelings in social contexts.

Item 3 indicates, on Table 5, that out of 200 respondents, 41 respondents $(20.4 \%)$ strongly agreed; 100 respondents (49.8\%) agreed; 29 respondents (14.4\%) disagreed; 6 respondents (3.0\%) strongly disagreed; and 24 respondents $(11.9 \%)$ were neutral, either for the benefit of doubt or lack of cultural knowledge. The mean of the participants is $M=3$, 71 , and the standard deviation is (S.Dev. =1.046). The finding gives the impression that some EFL students do not know that cross-cultural pragmatic competence is important in improving the communication skills of EFL learners for effective communication in a social context.

Item 4 on, Table 5, indicates that out of 200 respondents, 42 respondents (20.9\%) strongly agreed; 92 respondents (45.8\%) agreed; 34 respondents (16.9\%) disagreed; 4 respondents $(2.0 \%)$ strongly disagreed; and 28 respondents $(13.9 \%)$ were neutral in responding for the benefit of doubt or lack of cultural knowledge. The mean of the participants is $\mathrm{M}=3$, 67 , and the standard deviation is S.Dev. $=1.052$. The finding depicts that most EFL learners have no doubt in gaining experience and abilities to interpret words and expressions in a social context out of cross-cultural pragmatic knowledge.

Item 5 shows, on Table 5, that out of 200 respondents, 43 respondents $(21.4 \%)$ strongly agreed; 85 respondents (42.3\%) agreed; 36 respondents $(17.9 \%)$, disagreed; 8 respondents $(4.0 \%)$ strongly disagreed; and 28 respondents $(13.9 \%)$ were neutral in responding to item 5 , for either the benefit of doubt or lack of cultural knowledge. The mean of the participants is $M=3,60$, and the standard deviation is S.Dev. $=1.130$. The finding reveals that an average number of EFL learners are in agreement that "cross-cultural pragmatic competence could expose them to the knowledge of conventions, rules, beliefs and principles of different societies".

Research Question 3: What are the key challenges to EFL learners in cross-cultural communication?

The results of item 6 on Table 6 shows that out of 200 respondents, 37 respondents (18.4\%) strongly agreed; 88 respondents (43.8\%) agreed; 40 respondents (19.9\%) disagreed; 8 respondents $(4.0 \%)$ strongly disagreed; and 27 respondents $(13.4 \%)$ were neutral in responding to item 6 , either for the benefit of doubt or lack of cultural knowledge. The mean of the participants is $M=3.53$, and the standard deviation is $\mathrm{S} . \mathrm{Dev}=1.125$. The majority of the EFL students think that "in cross-cultural pragmatics, the speakers' utterances sometimes become difficult to interpret due to difficult words and implicit expressions". This shows that EFL learners are not endowed with cross-cultural pragmatic knowledge in the classroom irrespective of their linguistic knowledge in syntax and lexis.

Table 6. Represents item 6, item 7, item 8, item 9, and item 10 relating to questions (6 to 10) on the questionnaire and relevant to research question 3.

\begin{tabular}{|c|c|c|c|c|c|c|c|c|c|c|c|c|}
\hline & \multicolumn{2}{|c|}{ SA } & \multicolumn{2}{|c|}{ A } & \multicolumn{2}{|c|}{$\mathbf{N}$} & \multicolumn{2}{|c|}{$\mathrm{D}$} & \multicolumn{2}{|c|}{ SD } & \multirow[t]{2}{*}{ Mean } & \multirow[t]{2}{*}{ S.Dev. } \\
\hline & $\mathbf{N}$ & $\%$ & $\mathbf{N}$ & $\%$ & $\mathbf{N}$ & $\%$ & $\mathbf{N}$ & $\%$ & $\mathbf{N}$ & $\%$ & & \\
\hline Item 6 & 37 & 18.4 & 88 & 43.8 & 27 & 13.4 & 40 & 19.9 & 8 & 4 & 3.53 & 1.125 \\
\hline Item 7 & 31 & 15.4 & 98 & 48.8 & 29 & 14.4 & 37 & 18.4 & 4 & 2 & 3.58 & 1.065 \\
\hline Item 8 & 36 & 17.9 & 82 & 40.8 & 36 & 17.9 & 43 & 21.4 & 3 & 1.5 & 3.53 & 1.065 \\
\hline Item 9 & 53 & 26.4 & 87 & 43.3 & 22 & 10.9 & 38 & 18.9 & 0 & 0 & 3.78 & 1.044 \\
\hline Item 10 & 22 & 10.9 & 30 & 14.9 & 37 & 18.4 & 110 & 54.7 & 1 & 0.5 & 3.19 & 1.063 \\
\hline
\end{tabular}


Moreover, item 7 on Table 6 indicates that out of 200 respondents, 31 respondents (15.4\%) strongly agreed; 98 respondents (48.8) agreed; 37 respondents (18.4\%) disagreed; 4 respondents $(2.0 \%)$ strongly disagreed; and 29 respondents $(14.4 \%)$ were neutral in responding to item 7 either for the benefit of the doubt or lack of cultural knowledge. The mean of the participants is $M=3.58$, and the standard deviation is $\mathrm{S} . \mathrm{Dev}=1.065$. The finding implies the majority of the EFL learners are involved in situations where "the non-native speakers in cross-cultural interaction face hearing problems due to unfamiliar accents and pronunciations".

Item 8 in Table 6 shows that out of 200 respondents, 36 respondents (17.9\%) strongly agreed; 82 respondents (40.8\%) agreed; 43 respondents $(21.4 \%)$ disagreed; 3 respondents $(1.5 \%)$ strongly disagreed; and 36 respondents $(17.9 \%)$ were neutral in responding to item 8 , either for the benefit of the doubt or lack of cultural knowledge. Moreover, concerning item 8 , the mean of the participants is $M=3.58$, and the standard deviation is S.Dev $=1.065$. The finding reveals that the majority of the EFL speakers are of the view that "crosscultural communicators do face racial challenges, colour and cultural inferiority during an interaction.

Item 9 in Table 6 shows that out of 200 respondents, 53 respondents $(26.4 \%)$ strongly agreed; 87 respondents (43.3\%) agreed; 38 respondents (18.9\%) disagreed; zero (0) respondent $(0.0 \%)$ strongly disagreed; and 22 respondents $(10.9 \%)$ were neutral in responding to item 9, either for the benefit of doubt or lack of cultural knowledge. The mean of the participants is $M=3.78$, and the standard deviation is $\mathrm{S} . \mathrm{Dev}=1.044$. The finding shows that the majority of the EFL speakers proclaim "the cross-cultural communicators experience the problem of attitudinal and language barriers". Thus, they are victims of cultural shocks.

Item 10 in Table 6 shows that out of 200 respondents, 22 respondents (10.9\%) strongly agreed; 110 respondents (54.7\%) agreed; 30 respondents (14.9\%) disagreed; one (1) respondent $(0.5 \%)$ strongly disagreed; and 37 respondents $(18.4 \%)$ were neutral in responding to item 10 either for the benefit of doubt or lack of cultural knowledge. The mean of the participants is $M=3.19$, and the standard deviation S.Dev $=1.063$. The finding indicates that the majority of the EFL learners speculate "the cross-cultural communicators experience emotional interference due to clashes of norms and values of different cultures".

Results of qualitative analysis relevant to research question 4: "What are the personal views and experiences of both EFL teachers and their students on cross-cultural pragmatic in classroom situations?".

The responses are divided into two categories: categories A and B. Category A involves 10 teacher respondents. The teachers include six females and four males. Category B also comprises 20 student participants who responded to the interview guide questions.

Category A: The EFL Teachers' Responses to the four interview-guide questions (Q1, Q2, Q3 and Q4) are found in the Appendix A of the paper.

Category A comprises ten (10) teacher respondents. There are six females and four males. Therefore, the qualitative analysis in this study is based on themes that reference the interview questions found in Appendix A (for example, Theme 1: "Communicative Tasks in EFL Class by Teachers"; Theme 2: "Key Challenges Facing Their Students in Cross-Cultural Communication"; Theme 3: "Learning Strategies of Teachers to Help EFL Overcome Cross-cultural Communication Difficulties"; Theme 4: "Classroom Textbooks as Providing Cross-Cultural Pragmatic Information").

\subsection{Themes 1. "Communicative Tasks in EFL Class by Teachers"}

Out of 10 teacher participants, two lecturers (FT2 and MT1) mention class debate as a major activity of communicative task for their EFL students, while three lecturers (FT5, MT3 and MT4) claim that group discussion is the communication task preferable for their students. Moreover, FT3 and FT6 confirm conducting "role-play and pair-work" exercises as communicative tasks for their students in a classroom situation. For example, FT6 explains that "the role-play and pair-work tasks" are useful for enabling their EFL 
learners in becoming creative and improving upon their level of expressions in vocabulary and skills of performative utterances.

\subsection{Theme 2: "Key Challenges Facing Their Students in Cross-Cultural Communication"}

The finding shows that out of 10 participants, 4 lecturers (FT1, FT3, FT6 and MT2) pinpointed out problems in listening comprehension by students: FT1 explains that hearing problems is one the major problems of her EFL learners because of the series of complaint her students make concerning bad accents and wrong pronunciations. FT6 also speaks about students' difficulty in adjusting to new cultural conventions and practices. MT2 makes a submission on the difficulty to believe in cultural principles of different societies. On the other hand, MT3 and MT4 also touch on problems of racism and cultural inferiority, for example, MT3 proclaims that his students segregate themselves according to their ethnic groups in the classroom.

\subsection{Theme 3: "Learning Strategies of Teachers to Help EFL Overcome Cross-Cultural Communication Difficulties"}

The finding indicates that out of 10 participants, 3 lecturers FT4, MT3 and FT5 confirm using original English films and videos as language learning strategies: FT4 affirms making students watch original English films and videos in order to solve cultural communication problems among EFL students. He added that this encouraged them to accept the cultural norms and values of others. Moreover, MT3 claims that making their students watch original films and video tasks helps to create a state of attentiveness, observations and practices for effective pronunciations and intonation on the part of the EFL learners. Additionally, MT2 discloses that he introduces historical books, magazines, newspapers and textbooks to his learners in order to provide them with the needed exposure to the correct pronunciation from the native speakers.

\subsection{Theme 4: Classroom Textbooks as Providing Cross-Cultural Pragmatic Information}

The results show that 10 teacher participants (FT1; FT2; FT3, FT4; FT5; FT6; MT1; MT2; MT3; MT4) mentioned one major book titled Straightforward that is used for students in EFL classes apart from their personal supplementary textbooks. As a result, FT4 points out that the single textbook in her EFL class provides little information and only on linguistic knowledge such as vocabulary, grammar and pronunciation. In addition, FT5 also explains that the current book for English class provides knowledge of literal or logical meanings of words and not on cross-cultural knowledge. Equally, MT1 says the main textbook Straightforward falls short of cross-cultural pragmatic information in EFL class because there are no specific activities designed for enhancing the cross-cultural pragmatic competence of EFL learners in the classroom.

Category B: EFL students' responses to four interview-guide questions (Q1, Q2, Q3 and Q4) which are relevant to research question 4 of the study. The following themes emerged from their responses: Theme 5 "Communication Tasks from Teachers"; Theme 6 "Benefits or Challenges Students Face in Cross-Cultural Communication"; Theme 7 "Language Learning Strategies of EFL Teachers for Students"; and Theme 8 "Textbooks Used For EFL".

\subsection{Theme 5: "Communication Tasks of Teachers"}

The finding reveals that out of 20 interviewees, the participants SP2 and SP6 mention group discussion; the participants SP9, SP10 and SP19 mention debate; the participants SP3 and SP20 also lay emphasis on role-playing, and the participants (SP11 and SP17) stress on pair-work activities as communication tasks they experience in the classroom. For example, SP3 states that her teacher provides them with extracts from the school textbook Straightforward or from different textbooks for group discussion and dialogue but are unrelated to cross-culture knowledge. SP10 also says that his teacher has them involved in (group debate and video show) as communicative tasks on special topics such as "Hygiene, 
Marriage and Social Environments" and expected them to describe the characters, the moral lesson in the text and the types of information found in the video shown.

\subsection{Theme 6: "Benefits or Challenges Students Face in Cross-Cultural Communication"}

It is noted that, out of 20 participants, the respondents SP4, SP8 and SP12 raise the issue of problems of cultural segregation challenges they face in a classroom situation. At the same time, SP9, SP17, SP19 and SP20 mention a lack of communication due to language barriers, racism and cultural inferiority complex as a problem. For example, SP4 explains that, as they come together to learn EFL, they usually feel comfortable in their small ethnic groups sorted by their cultures and mother tongue rather than generalising EFL groups in the classroom context. Again, SP19 says that, by his observation, African French speakers stay away from their EFL counterparts of Turkish speakers and Arabic speakers who also feel uncomfortable staying with African Anglophone speakers due to language and cultural differences. Furthermore, SP17 claims they have been experiencing cultural trauma due to signs of racism and cultural stigma related to not being accepted in some cultural groups for interactions and group studies.

\subsection{Theme 7: "Language Learning Strategies of EFL Teachers for Students"}

The results show that out of 20 participants, SP3, SP4 and SP7 mention "memorization exercises"; SP2, SP11 and SP14 lay emphasis on repetition drills, while SP10, SP15 and SP17 stress on cooperative notetaking as language learning strategies they do experience in the classroom by their teachers. As an example, SP7 claims that their teacher conducts memorization to help them develop the ability of native pronunciation, and SP14 explains that they undergo repetition drills in order to develop the fluency ability. Furthermore, as an example, SP17 explains their teachers conduct cooperative notetaking in order to help them overcome some of their naiveties in cross-cultural interaction.

\subsection{Theme 8: "Textbooks Used for EFL"}

All the 20 student participants reference a textbook titled Straightforward. For example, SP15 says that their "textbook seems unique in EFL classrooms", but they lack information on cross-cultural awareness. Moreover, SP8 and SP14 point out that the textbook Straightforward in EFL class provides them with few information on linguistic knowledge that comprises vocabulary, grammar and pronunciation and not on cross-cultural pragmatic knowledge. Likewise, SP1 and SP6 state that although the textbook Straightforward is used daily during contact hours, it does not contain cross-cultural knowledge and activities. For SP17, she observes nothing concerning intercultural awareness when reading Straightforward.

\section{Discussion}

The findings in this study reveal that the gaps related to these linguistic challenges are due to the inadequate knowledge of cross-cultural pragmatic competence for creating complete success in social communication. The study explores the dynamics of EFL learners, the key challenges facing them and raises concerns on the personal views and experience of teachers and students regarding cross-cultural pragmatic competence. Hence, the prime objective of this paper is related to the enhancement of the cross-cultural pragmatic competence of EFL learners in classroom circumstances.

The findings indicate that the concerns raised by the EFL teachers and students seem significant in this paper and must be addressed in promoting the language proficiency of the EFL learners. The findings reveal the core points of students' performance on the comprehension of cross-cultural pragmatic competence with regard to gender, language groups, the field of studies and age. At the gender level, the EFL female students perform slightly better in cross-cultural pragmatic competence than their male counterparts. Findings reveal on a language group basis that the EFL students of Anglophone background perform better in cross-cultural pragmatic competence than their counterparts with Arabic, Francophone and Turkish backgrounds. Sayahi [36] confirms that the teaching and learning 
of EFL in the above mentioned countries is better comparing to the performance level of language competency between Arabic-French and Arabic-English learners in Maghreb countries such as Algeria, Libya, Mauritania, Morocco and Tunisia, all of them with Arabic backgrounds. The findings concerning the field of studies depict that the students of the social sciences perform slightly above their pure sciences counterparts. Explaining the core point on positive and social sciences, Morgan [26] looks at pragmatism as an important domain of philosophy that entails problem-solving experience relative to gaining cultural knowledge from human activities. Furthermore, findings in this paper on age gaps depict the maturity of ages between (25-34), and it is slightly significant in the performance on comprehension of pragmatic competence. By this perception, Polovna [37] asserts that it is important to usher language learners into new platforms regarding age and experience of cultural communication for better interpretation of connotative utterances. Findings imply that an average number of the EFL student respondents agrees that "cross-cultural pragmatics is important in EFL context because it creates the awareness on how the same words can have different meanings in different contexts". In this concept, the two researchers spell out that the prospective fields of misrepresentation and failures in social communication are destined to materialize during the interactive communication among EFL learners in a social context [38].

The findings show a positive impression that cross-cultural pragmatic competence is essential in the EFL context because it provides an opportunity for EFL learners to communicate effectively in social contexts. For Hall et al. [39], the EFL instructors must incorporate pragmatic topics well relative to classroom scheduled book-topics such as topicopening agendas, topic-sustaining matters, topic-maintaining opinions, topic-condemning acts and topic-closing's dialogues that involve expressions such as the following: "What's up now?"; “What else?"; "What's going on?"; “What's wrong?"; “What next?"; "I am overwhelmed"; "We are delighted"; "Enough of that"; "How far?"; "Your Excellency"; and "Your highness".

Nevertheless, the findings concerning the key challenges confronting EFL students on cross-cultural communication in Table 6 shows that the majority of EFL respondents underline communication difficulties with regard to the wrong pronunciation of words, unfamiliar language accents, bias interpretations, attitudinal complex, colour differences and language barriers, use of difficult words, concerns raised on racism, cultural inferiority sentiments and unfamiliar terminologies as parts of cross-cultural pragmatic challenges. Pedagogically, the language philosopher Yule [40] describe these key challenges of mistakes or errors as "bad speech or bad language" because they are emotionally judged, and judgments in reference to language principles and terminologies become a violation of norms and rules in a target language.

The findings on EFL teachers' personal views and experience raise issues on classroom tasks such as dialogue, role-play, debate, repetition drills and presentation that are essential for helping EFL students overcome stage fright relative to cultural differences. For example, in the interview section, the second male teacher respondent (MT2) adds that the communicative tasks allow students to develop their speaking abilities for their everyday interactions with one another. However, from the pedagogical point of view, Tsutagawa [41] proclaims that despite all the classroom language tasks conducted by EFL instructors, role-play becomes the centre of attraction of teaching activities for developing the language skills of EFL students with respect to performing credibly in a cross-cultural pragmatic context.

Moreover, on students' personal views and experience on cross-cultural pragmatic competence, the findings disclose that the complaints of students on cross-cultural challenges in EFL context are due to different cultural backgrounds and beliefs of others that seem difficult to be conversant in within a short time.

Another important issue is related to the single textbook Straightforward that is used and seems inadequate for developing pragmatic competence among EFL students in classroom situations. Consequently, Dendenne [42], Matsuoka et al. [43] and Kafi et al. [44] 
caution contemporary textbooks and ascertain that textbooks are among the most important instructional materials that have to be considered as the vital backbone for second or foreign language learning. In this situation, the study suggests that cross-cultural pragmatic competence should remain the basic framework for natural interaction with one another, especially in classroom circumstances involving appropriate textbooks and activities such as the reading of authentic materials, cultural-oriented materials and cross-cultural debatable topics. Moreover, this paper draws our attention on the communicative language teaching approach of $\mathrm{Wu}$ [27] that seems remarkably significant in enhancing pragmatic competence of EFL learners. The approach is student centred and can permit students engagement in communicative activities.

Therefore, the findings of this paper arouse our attention to situations concerning cross-cultural pragmatic competence and highlight some suggestions that seem significant in enhancing the pragmatic competence of students regarding foreign language teaching and learning. Furthermore, the literature review related to this paper seems significant since it emphasises the interpretation of words and expressions that consider the norms and values of a target language in social contexts. In view of this, Norton and Toohey [45] confirm that learning grounds, such as in the classroom environment, must be one of the considered centres for acquiring language skills and cultural knowledge.

\section{Conclusions}

The findings of the study indicate that EFL students are not furnished with crosscultural pragmatic competence in the classroom and must be provided with classroom tasks to develop both explicit and implicit communicative competence for a sustainable English learning environment. They also lack textbooks comprising pragmatic knowledge. The study further reveals that EFL teachers' pay little attention to cross-cultural pragmatic knowledge and classroom activities in the EFL context. These situations need to be addressed in order to help the EFL learners in enhancing cross-cultural pragmatic competence and to communicate meaningfully in a social context. It is important to state that cross-cultural pragmatic competence can bring to perfection the English language skills of EFL learners.

In the midst of cross-cultural interaction, a communicator speaking a non-native language or L2 may easily create language miscommunication, and this situation becomes the central tendency in day-to-day activities inside and outside of classroom circumstances. For instance, taking "coffee or tea" in a breakfast context may be a "dessert after a meal or before the meal" for one's culture, and it may bring misunderstanding and disappointment to some other communicators when it is defined as "breakfast only" due to some cultural norms and interpretations. As proof of this, the paper tends to raise the tactical awareness of ELF teachers and learners on cross-cultural pragmatic competence. Hence, on the pedagogical point of view, there is a need to consider the communication terms for values and norms by the calibre of words and expressions used amidst target language learners. Based on the results of this study, there is a need to caution EFL teachers and learners to be circumspect when dealing with cross-cultural shocks among foreign students in classroom circumstances, and when things do not happen the way we expected or thought, one must be flexible, adjustable and tolerant of overcoming cultural emotions inside and outside school environments.

\section{The Pedagogical Implication}

The pedagogical implication of this study is to intensify the awareness and the importance of cross-cultural pragmatic competence in a target language, especially in the EFL context. $\mathrm{Wu}$ [27] asserts that the basic principle of communicative Language Teaching (CLT) must be virtual "Learner-Centred", involving communicative activities such as group discussion, debate, dialogue, role play, reading practices and presentations. Furthermore, Jie [14] and Kecskes [46] suggest that the development of pragmatic competence must be a motivation for cross-cultural communicators to improve upon their communicative clarity and fluency in EFL or ESL settings. In this manner, EFL teachers are called upon 
to develop EFL students' motivation for intercultural relations through cultural related tasks in classroom environments for socialization as well as certification for globalization and partnership. Rumyantseva et al. [47] also highlight that, for shaping sustainable language learning environment, forming multicultural personality through language leaning is crucial.

Consequently, the findings in this study alert us on the urgent need for teachers to abreast themselves with the knowledge of cross-cultural pragmatics and make it teachable, learnable and achievable. Hence, the unpredictable occasions may engage L2 learners in complex scenarios lacking practical information in communication. For this reason, Zakaria et al. [48] and Walsh [49] caution teachers to be circumspect in handling issues pertaining to EFL learners and claim that the high-level compassion of communicative competency is found within the interactional gatherings of cross-cultural communicators on the social platform.

Therefore, because of the findings in this paper and for the tendency of global connections, some positive recommendations on cross-cultural activities must be observed by teachers for the enhancement of EFL learners' pragmatic competency. In this manner, Alemi et al. [50] assume that English textbooks propagate cultural knowledge for L2 learners, and teachers must locate cross-cultural information on internet journal language, culture and society for classroom's achievements. Apart from classroom tasks and other curriculum, this paper suggests some extracurricular activities such as cross-cultural trips for exchange programs, cross-cultural games and festivities, cross-cultural quizzes and debates, cross-cultural theatrical arts, drama or short sketches and cross-cultural expositions. These extracurricular activities seem practically important and must be observed with regard to cross-cultural awareness, sentiment and generalization.

\section{Limitations}

The limitations in this paper are important. The questionnaire at the interview questions has been tested on a pilot basis after consulting three experts in this field of research. Moreover, the pilot study has been a step in the right direction to validate the components of the questionnaire and the interview questions, such as the following: the content, the instructions, sentence structures, and to determine the reliability of the questionnaire and the interview questions. The questionnaire and the interview questions of the study have been validated by administering them on a pilot basis to twenty five (25) students of first-year undergraduates comprising 13 females and 12 males, all of them from CIU (Cyprus International University) who voluntarily responded to the questionnaire. Five (5) teachers and (10) students responded to the interview questions, and approximately 40 to 50 minutes was spent on each respondent. The pilot tests have been conducted on 3 and 4 April 2019. Furthermore, in relation to the study concerning cross-cultural pragmatic competence, the pilot study places into consideration the different continents involving respondents from Africa, Asia, Europe, America and others to establish some facts concerning the validity of the instruments for data collection. Furthermore, the final questionnaire and interview questions were structured based on the reliable responses given by the pilot-test participants. The limitation on the study population of first-year CIU EFL students presents more opportunities for further research that can involve more participants from other sectors of language teaching and learning in Northern Cyprus and elsewhere in regards to cross-cultural pragmatic competence.

\section{Further Research}

Researchers can conduct studies on the following: (1) motivational factors relating to cross-cultural pragmatic competence; (2) specific classroom activities for the enhancement of cross-cultural pragmatic competence in EFL context; (3) interactive strategies for developing cross-cultural pragmatic competence in EFL context. 
Author Contributions: Conceptualization, B.B. and F.S.; Methodology, B.B. and F.S. and B.M.; software, B.B.; Validation, B.B., F.S. and B.M.; formal analysis, B.B., F.S. and B.M.; investigation, B.B.; resources, B.B. and F.S., and B.M.; data curation, B.B.; writing-original draft preparation, B.B.; writing-review and editing, B.B., F.S., and B.M.; visualization, B.B.; supervision, F.S. and B.M.; project administration, F.S.; funding acquisition, B.B., F.S. and B.M. All authors have read and agreed to the published version of the manuscript.

Funding: This research received no external funding.

Institutional Review Board Statement: Ethical review and approval were waived for this study, due to reason that it did not give any harm to animals and human beings.

Informed Consent Statement: Informed consent was obtained from all subjects involved in the study.

Data Availability Statement: The study did not report any data.

Conflicts of Interest: The authors declare no conflict of interest.

\section{Appendix A. A Questionnaire on Cross-Culture Pragmatic Competence}

Please give answers to the following questions for research purposes and all information will be treated in the strictest confidence and do not enter your name.

Your collaboration is cordially important in this research by providing answers to the questions below. Thank you.

PART 1

Demographic Information:

Gender: 1. Male ( ) 2. Female ( )

Language Group: 1. English ( ); 2. French ( ); 3. Arab ( ); 4. Others ()

Field of Study: 1. Physical Sciences ( ); 2. Social Sciences ( )

Age: A. 17-24 ( ); B. 25-34 ( ); C. 35-44 ( ); D: 45 and above ( )

Continent: A. Africa ( ) B. Asia ( ) C. Europe ( ); D. America ( ); E. Others ( )

PART 2

SECTION A: Relevant to Research Question 1

Students' level of competency on comprehension of pragmatic competence in regard of their gender, language group (mother tongues), fields of studies and age?

Please tick one letter from the options (A, B, C and D) that seems to give the correct answer of each item.

$1=\mathrm{A} ; 2=\mathrm{B} ; 3=\mathrm{C} ; 4=\mathrm{D}$

1. Jonas is from Ankara. His friend Albert has recently moved to Ankara.

Jonas: "How do you like Ankara so far?"

Albert: "I love it."

*What does Albert possibly mean?

A. He thinks Ankara is a normal city.

B. He is yet to see much of Paris.

C. He thinks the city needs more great changes.

D. He likes Ankara and enjoys living there.

2. Paul and Peter are professors at a college. They are chatting about a student called Ibrahim.

Paul: "How did you like Ibrahim's paper?"

Peter: "Well, I thought it was well-typed."

*What does Peter probably mean?

A. He did not like Ibrahim's essay.

B. He did not really remember Ibrahim's essay.

C. He thought the Ibrahim's topic was interesting.

D. He liked Ibrahim's essay quite a lot.

3. Mary and Margaret are secondary school teachers. Mary is considering teaching

Chemistry, but Margaret has heard it is really challenging. 
Margaret: "I don't know, but people say it's really involving".

*What does Margaret probably mean?

A. She assumes the course may not be very difficult.

B. She thinks Mary can teach that course

C. She recommends not teaching that course.

D. She feels Mary should not listen to what people say about the course.

4. Ben and Julie are classmates and discussing about school and courses. Ben is taking French

literature this semester.

Julie: "How are you doing in French literature?"

Ben: "So, did you watch that basketball game yesterday?"

*What does Ben probably mean?

A. The content of yesterday's lesson was completely irrelevant to a basketball game.

B. He is doing badly in French literature.

C. French literature is like an easy game for him.

D. He is doing so well in French literature that there is no need to talk about it.

5. Amidu, a company driver, packs the company's car to take his lunch. Frank, a worker in the company, enters Amidu's office and gets the key to use the car for an emergency errand.

Frank: "The car is almost out of fuel."

*What does Frank probably mean?

A. He wants Amidu to get fuel for the car.

B. He does not want Amidu to drive the car again.

C. He does not want to drive the car himself.

D. He wants Amidu to continue with his lunch.

6. Abraham is trying to find an apartment in Canada. He just looked at a place and is telling his friend Felicia in short dialogue about it.

Felicia: "So, is the rent high?"

Abraham: "is the Pope a Catholic?"

*What does Abraham probably mean?

A. He does not want to talk about the rent.

B. The rent is high.

C. He did not understand Felicia's question.

D. The rent is not very high.

7. Mr. Brown and Mr. White are teachers trying to eat at a restaurant close to their school. Mr. Brown buys something to eat, but Mr. White cannot make a decision on what to eat.

Mr. White: "How do you like what you're eating?"

Mr. Brown: "Well, let's just say it's colourful."

*What does Mr Brown probably mean?

A. He thinks it is important for food to look good.

B. He likes the food.

C. He wants Mr White to try something colourful.

D. He does not like the food much.

8. Mr. Smith promised to help her sister Sheila move to a new bed room. That day, he packed the books from the table while Sheila moved the heavy table.

Sheila: "Thanks, you've been terribly helpful."

*What does Sheila probably mean?

A. Mr Smith helped her a lot.

B. Packing the books was really important as it needed special care.

C. Mr Smith is weak. 
D. Mr Smith was not helpful to her at all.

9. Simon asks about his fiancée Paulina from his friend David.

Simon: "You know. I've been trying to know if you went out with Paulina?"

David: "Paulina is not really my type."

*What does David probably mean?

A. He is not sure of his emotions.

B. He is talking bad about Paulina as he does not like her.

C. Paulina is somehow his best type.

D. They did not go out.

10. Mrs. Alibah runs into her colleague teacher Mrs. Ali who recently had a promotion interview.

Mrs Alibah: "By the way, did you get that promotion you applied for?"

Mrs Ali: "Good God, I'm so tired of this cold weather."

*What does Mrs Ali probably mean?

A. She does not want to talk about the promotion interview.

B. She is bored with the promotion interview.

C. She did not understand Mrs Alibah's question.

D. She could not attend the interview because of cold weather.

Answers to comprehension test on pragmatic competence. Questions (11-20)

11. D. He likes Paris and enjoys living there.

12. A. He did not like Ibrahim's essay.

13. C. She recommends not teaching that course.

14. B. He is doing badly in French literature.

15. A. He wants Amidu to get fuel for the car.

16. B. The rent is high.

17. D. He does not like the food much.

18. D. Mr Smith was not helpful to her at all.

19. D. They did not go out.

20. A. She does not want to talk about the promotion interview.

SECTION B: Relevant to Research Question 2

Perceptions of EFL learners in Cross-cultural Pragmatic Competence.

Note: Definitions of Terms

*Pragmatics is the study of meanings of words and expressions in a context. It is the study of the use of linguistic signs, words and sentences or expressions in social contexts.

${ }^{*}$ Cross-cultural Pragmatics is the study of linguistic signs, words and expressions, accepted by language users from different cultural backgrounds.

${ }^{*}$ Cross-cultural Pragmatic Competence is the ability to understand and interpret words and expressions to convey meanings under social context.

Note SA: Strongly Agree; A: Agree; N: Neutral; D: Disagree; SD: Strongly Disagree

Please tick only one letter from the options (A, B, C and D) that seems suitable to each item.

Note: 1 = SA: Strongly Agree; 2 = A: Agree; $3=$ N: Neutral; $4=$ D: Disagree; $5=$ SD: Strongly Disagree.

1. Cross-cultural Pragmatics is important in EFL because it creates the awareness of how the same words can have different meanings in different contexts.

1 = SA: Strongly Agree; 2 = A: Agree; $3=\mathrm{N}$ : Neutral; 4 = D: Disagree; 5 =SD: Strongly Disagree

2. Cross-cultural pragmatic competence is essential in EFL because it gives opportunity to EFL learners to communicate and share their personal ideas, thoughts and feelings in a context.

1 = SA: Strongly Agree; 2 = A: Agree; 3 = N: Neutral; 4 = D: Disagree; 5 =SD: Strongly Disagree 
3. Cross-cultural pragmatic competence is important because it helps to improve upon the communication skills of EFL learners to understand utterances made in a social context.

1 = SA: Strongly Agree; 2 = A: Agree; 3 =N: Neutral; 4 = D: Disagree; 5 =SD: Strongly Disagree

4. Cross-cultural pragmatic competence is important in EFL because it is a platform for EFL learners to gain experience and ability of interpreting words and expressions in social situations.

1 = SA: Strongly Agree; 2 = A: Agree; 3 = N: Neutral; 4 = D: Disagree; 5 = SD: Strongly Disagree .

5. Cross-cultural pragmatic competence exposes EFL learners to knowledge of conventions, rules, beliefs and principles of different societies.

1 = SA: Strongly Agree; 2 = A: Agree; 3 = N: Neutral; 4 = D: Disagree; 5 = SD: Strongly Disagree

SECTION C: Relevant to Research Question 3

Cross-cultural Pragmatic Challenges

6. In cross-cultural pragmatics, the speakers' utterances sometimes become difficult to interpret due to difficult words and unfamiliar terms.

1 =SA: Strongly Agree; 2 = A: Agree; 3 = N: Neutral; 4 = D: Disagree; 5 =SD: Strongly Disagree

7. Communicators in cross-cultural interaction face hearing problems due to unfamiliar accents and pronunciations.

1 =SA: Strongly Agree; 2 = A: Agree; 3 = N: Neutral; 4 = D: Disagree; 5 =SD: Strongly Disagree

8. Cross-cultural communicators face problems of racism or color or cultural inferiority during interaction.

1 =SA: Strongly Agree; 2 = A: Agree; 3 = N: Neutral; 4 = D: Disagree; 5 =SD: Strongly Disagree

9. Cross-cultural communicators experience problem of attitudinal and language barriers.

1 = SA: Strongly Agree; 2 = A: Agree; 3 = N: Neutral; 4 = D: Disagree; 5 = SD: Strongly Disagree

10. Cross-cultural communicators experience emotional interference due to clashes of norms and values of different cultures.

1 =SA: Strongly Agree; 2 = A: Agree; 3 = N: Neutral; 4 = D: Disagree; 5 =SD: Strongly Disagree

Part 3: Relevant to Research Question 4.

Interview Guide Questions.

Personal views and experience of CIU EFL teachers and students on cross-cultural pragmatic in classroom circumstances.

Interview Guides for Teachers.

Note: Cross-cultural communication is the communication that occurs between people who may have different cultural perspectives of interpretation of words and expressions (Stringer and Cassidy, 2009).

Note: Cross-cultural Pragmatic Competence is the ability to understand and interpret words and expressions to convey meanings in social context.

Interview Questions.

(1). What communicative tasks do you usually conduct in the classroom teaching to improve your students' communicative ability and pragmatic competence? What challenges or difficulties or benefits do your students face when you conduct communication tasks to improve their communicative ability?

(2). What challenges or benefits do your students face in cross-cultural communication in classroom situations?

(3). What kind of language learning strategies (learning activities) do you conduct to help your EFL students overcome their cross- cultural communication challenges or difficulties in classroom multicultural situations? 
(4). To what extent do the textbooks you use in EFL class provide information on crosscultural pragmatics?

Interview Guides for Students.

Note: Cross-cultural communication is the communication that occurs between people who may have different cultural perspectives (Stringer and Cassiday, 2009).

Note: Cross-cultural Pragmatic Competence: is the ability to understand and interpret words and expressions to convey meanings under social context?

Interview Questions.

(1). What communicative tasks do your English teachers usually conduct in the classroom teaching to improve your communicative ability and pragmatic competence? What challenges or difficulties or benefits do you face when your teachers conduct communication tasks to improve your communicative ability?

(2). What are the challenges or difficulties or benefits do you face in cross-cultural communication with student colleagues in classroom?

(3). What kind of language learning strategies (learning activities) do your teacher conduct to help you overcome your cross- cultural communication challenges or difficulties in classroom multicultural situations?

(4). To what extent do the textbooks you use in EFL class provide information on crosscultural pragmatics?

\section{References}

1. Pamugkas, N.A.R.; Wulandari, L.T. Pragmatics in EFL Classroom: Avoiding Pragmatic Failure in Cross-Cultural Communication. J. Eng. Teach. Res. 2020, 5, 74-91.

2. Mey, J.L. Pragmatics: An Introduction, 2nd ed.; Wiley-Blackwell: New York, NY, USA, 2001.

3. Lo Castro, V. An Introduction to Pragmatics: Social Action for Language Teachers; University of Michigan Press: Ann Arbor, MI, USA, 2003.

4. Koester, J.; Lustig, M.W. Intercultural communication competence: Theory, measurement, and application. Int. J. Intercult. Relat. 2015, 48, 20-21. [CrossRef]

5. Taguchi, N. Teaching Pragmatics: Trends and Issues. Annu. Rev. Appl. Linguist. 2011, 31, 289-310. [CrossRef]

6. Mulyana, D. Cultures and Communication: An Indonesian Scholar's Perspective; Penerbit PT Remaja Rosdakarya: Bandung, Indonesia, 2012.

7. Dash, S.K. A Study of the Socio-Pragmatic Competence of the Teachers in Higher Education in Odisha. Int. J. Eng. Res. 2015, 1, 2186-2455.

8. Alzeebaree, Y.; Yavuz, M.A. Realization of the Speech Acts of Request and Apology by Middle Eastern EFL Learners. Eurasia J. Math. Sci. Technol. Educ. 2017, 13, 7313-7327. [CrossRef]

9. Mohammadzadeh, B.; Razı, Ö.; Yavuz, M.A. Comprehension of Conversational Implicatures by Students of the ELT Department. Folk./Ed. 2019, 25, 373-380.

10. Timpe, V. Strategic Decoding of Socio-pragmatic Assessment Tasks-An exploratory think. Sec. Lang. St. 2012, 30, 109-246.

11. Levine, G.S. Code Choice in the Language Classroom; Channel View Publications: Bristol, UK, 2011.

12. Rafieyan, V.; Majid, A.; Eng, L.S. Relationship Toward Target Language Culture Instruction and Pragmatic Comprehension Development. Engl. Lang. Teach. 2013, 6, 125-132. [CrossRef]

13. Röver, C. Testing ESL Pragmatics: Development and Validation of a Web-Based Assessment Battery; Peter Lang: Frankfurt, Germany, 2005.

14. Jie, F. A study on pragmatic failure in cross-cultural communication. Online Submiss. 2010, 7, 42-46.

15. Bouchard, J. Pragmatic failure and language ideologies: Challenges in the Japanese EFL context. Stud. Cul. 2011, 49, 69-114.

16. James, W. Pragmatism, a New Name for Old Ways of Thinking: Popular Lectures in Philosophy; Hardpress Publication: Los Angeles, CA, USA, 2012.

17. Chen, C.-Y.D.; Chang, M.-H.; Chen, Y.-S. American and Chinese complaints: Strategy use from a cross-cultural perspective. Intercult. Pragmat. 2011, 8, 253-275. [CrossRef]

18. Tajeddin, Z.; Moghadam, A. Interlanguage pragmatic motivation: Its construct and impact on speech act production. RELC J. 2012, 43, 353-372. [CrossRef]

19. Benadla, L. The Competency-Based Language Teaching in the Algerian Middle School: From EFL Acquisition Planning to its Practical Teaching/Learning. Arab World Engl. J. 2012, 3, 144-151.

20. Borni, I.E. The Effects of Algerian Culture on EFL Students' Speaking English Outside Classroom Case Study; Mohamed Khider University of Biskra: Biskra, Algeria, 2012. 
21. Guo, Y. Chinese and American Refusal Strategy: A Cross-Cultural Approach. Theory Pract. Lang. Stud. $2012,2,247-256$. [CrossRef]

22. Maccoby, E.E. Gender and Group Process: A Developmental Perspective. Curr. Dir. in Psy. Sci. 2002, 11, 54-58. [CrossRef]

23. Gulzar, M.A. Code-switching: Awareness about its utility in bilingual classrooms. Bull. Ed. Res. 2010, 32, $23-44$.

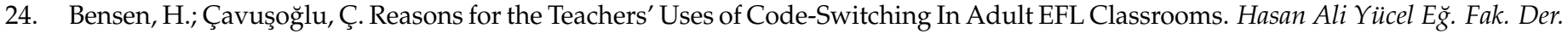
2013, 10, 69-82.

25. Ishihara, N.; Cohen, A.D. Teaching and Learning Pragmatics: Where Language and Culture Meet; Routledge: Abingdon, VA, USA, 2014.

26. Morgan, D.L. Pragmatism as a Paradigm for Social Research. Qual. Inq. 2014, 20, 1045-1053. [CrossRef]

27. Wu, W. Misunderstandings of Communicative Language Teaching. Engl. Lang. Teach. 2008, 1, 50-53. [CrossRef]

28. Weeger, M.J. A comparison of the two theories of Learning-Behavioural and Constructivism: As applied to face-to-face and online learning. E-Leader 2012, 1, 3-10.

29. Sunal, D.W. The Learning Cycle: A Comparison of Models of Strategies for Conceptual Reconstruction: A Review of the Literature. Available online: http:/ / astlc.ua.edu/ScienceInElem\&MiddleSchool/565LearningCycle-ComparingModels.htm (accessed on 10 September 2021).

30. Denzin, N. Moments, mixed methods, and paradigm dialogs. Qual. Inq. 2010, 16, 419-427. [CrossRef]

31. Fraenkel, J.; Wallen, N.; Hyun, H. How to Design and Evaluate Research in Education 10th Edition; McGraw-Hill Education: New York, NY, USA, 2018.

32. Seidman, I. Interviewing as Qualitative Research: A Guide for Researchers in Education and the Social Sciences 5th Edition; Teachers College Press: New York, NY, USA, 2019.

33. Folkestad, B. Analyzing Interview Data: Possibilities and Challenges; Euro sphere Working Paper Series; EWP: Bergen, Norway, 2008.

34. Creswell, J.W. Educational Research: Planning, Conducting, and Evaluating Quantitative and Qualitative Research, 4th ed.; Merrill: Upper Saddle River, NJ, USA, 2012.

35. Braun, V.; Clarke, V. Using thematic analysis in psychology. Qual. Res. Psy. 2006, 3, 77-101. [CrossRef]

36. Sayahi, L. Diglossia and Language Contact: Language Variation and Change in North Africa; Cambridge University Press: Cambridge, UK, 2014.

37. Povolna, R. Pragmatic Awareness in Teacher Education. Acta Acad. Karviniensia 2012, 12, 148-158. [CrossRef]

38. Al-Saidi, A.H.S.; Rashid, S. Investigating Socio-pragmatic Failure in Cross-cultural Translation: A Theoretical Perspective. In Arab World English Journal (AWEJ) Special Issue on Translation; SSRN: Amsterdam, The Netherlands, 2015.

39. Hall, G.; Cook, G. Own-Language Use in EFL: Exploring Global Practices and Attitudes; British Council: London, UK, 2013.

40. Yule, G. The Study of Language, 4th ed.; Cambridge University Press: Cambridge, UK, 2010.

41. Tsutagawa, F. Future directions in pragmatics assessment. TESOL Appl. Ling. 2012, 2, 43-45.

42. Dendenne, B. The Pragmatic Suitability of the Algerian ELT Secondary School Textbooks: A Focus on Speech Acts. Rev. Sci. Hum. 2013, 125-146.

43. Matsuoka, W. Searching for the Right Words: Creating Word Lists to Inform EFL Learning. In Current Perspectives in Second Language Vocabulary Research; Hirsh, D., Ed.; Peter Lang: Bern, Switzerland, 2012.

44. Kafi, Z.; Ashraf, H.; Motallebzadeh, K. English Textbooks and Cultural Attitudes of Iranian EFL Learners: Investigating a Relationship. IJLLALW 2013, 4, 23-35.

45. Norton, B.; Toohey, K. Identity, language learning, and social change. Lang. Teach. 2011, 44, 412-446. [CrossRef]

46. Kecskes, I. Intercultural Pragmatics; Oxford University Press: New York, NY, USA, 2014.

47. Rumyantseva, E.; Nekora, N.; Kozhevnikova, L. Negative Pragmatic Transfer as a Factor Jeopardizing Formation of Multicultural Personality in RFL Classroom (the case of request speech act). In Proceedings of the International Conference on European Multilingualism: Shaping Sustainable Educational and Social Environment; Atlantis Press: Amsterdam, The Netherlands, 2019; pp. 195-202.

48. Zakaria, N.; Rahma, N.H.; Aripin, N.; Jasman, N.H.; Ibrahim, N.A. Exploring Perceptions of Role Play Activities in English as Second Language (ESL) Classrooms. IJEAT 2019, 8, 868-872.

49. Walsh, S. Exploring Classroom Discourse: Language in Action; Routledge: London, UK, 2011.

50. Alemi, M.; Tajeddin, Z. Pragmatic Rating of L2 Refusal: Criteria of native and non-native English Teachers. TESL Can. J. 2013, 30, 63-81. [CrossRef] 